\title{
Determining the count median diameter of nanoaerosols by simultaneously measuring their number and lung deposited surface area concentrations
}

\section{Brief communication}

S. Bau ${ }^{1}$, O. Witschger ${ }^{1}$, F. Gensdarmes ${ }^{2}$ and D. Thomas ${ }^{3}$

${ }^{1}$ Institut National de Recherche et de Sécurité, Laboratoire de Métrologie des Aérosols, Rue du Morvan CS 60027, 54519 Vandoeuvre, France

sebastien.bau@inrs.fr

${ }^{2}$ Institut de Radioprotection et de Sûreté Nucléaire (IRSN), PSNRES/SCA/LPMA, Saclay, Gif-sur-Yvette, 91192, France.

${ }^{3}$ Laboratoire de Réactions et Génie des Procédés - Université de Lorraine, 1, rue Grandville - BP 20451, 54001 Nancy Cedex, France

Keywords: nanoaerosol; count median diameter; lung-deposited surface area concentration 


\section{Abstract}

Due to the increasing use of nanomaterials in research and product development, it is probable that the number of situations of occupational exposure to them is also rising. The same is true for the number of workers. Although current research in nanotoxicology is far from conclusive, it is clear that relying on mass concentration and chemical composition alone is not appropriate in all cases and alternative measurement methods and approaches need to be developed.

In this work, we propose a method based on simultaneous size-integrated measurements of two particle concentrations (number and lung-deposited surface area, CNC/NSAM), and on the estimation of the average size of potentially inhaled particles from the combination of these measurements. The proposed method could be part of a measurement strategy that is practical as it would use field-portable, commercially available aerosol instruments. In the absence of instruments providing real-time sizeresolved measurements, this original approach can be carried out as considering that the ratio of these concentrations is a monotonous function of particle size. Indeed, the latter function depends only on the geometric standard deviation of airborne particle number size distribution, assumed to be lognormal.

Compared to SMPS data for polydisperse aerosols having three chemical natures with count median diameters ranging from 64 to $177 \mathrm{~nm}$, experimental results were obtained with acceptable relative discrepancies of $\pm 30 \%$. Though the method proposed is less accurate than traditional instruments like SMPS, it can be used for workplace air monitoring or as a screening tool to detect the presence of airborne nanoparticles. 


\section{Introduction}

Although nanomaterials are used increasingly in various fields such as energy, health, cosmetics, materials etc, uncertainties remain regarding their potential health effects. In parallel, the number of occupational inhalation exposure situations is probably rising, leading to the recent proposal of generic strategies for assessing workplace exposure to airborne nanomaterials (e.g. Brouwer et al., 2009; Methner et al., 2010; Ramachandran et al., 2011; Witschger et al., 2012). In addition to chemical composition, these strategies indicate that a variety of parameters is required to characterize exposure to airborne nanomaterials. Among them, particle concentration and size play an important role (e.g. Wang et al., 2011), since they provide information on the quantity and the region of the respiratory tract where inhaled nanoparticles will be deposited and potentially interact.

Although the choice of the metric (number, surface area, mass concentrations) to use is still being debated, investigations into the performances of real-time instruments measuring airborne particle concentrations have risen. Indeed, there is a constant need to increase knowledge on the behavior of instruments used to measure submicron aerosols in both laboratory studies and in workplace environments.

Particle size measurement is a more complex issue.

The gold standard technique employed to determine both overall (agglomerate/aggregate) and primary particle sizes is electron microscopy (EM). Obtaining and analyzing sufficient images in order to have a statistically significant analysis (Mavrocordatos et al., 2007) is not only time consuming, but the duration of sampling and sampling device efficiency must be defined with great care to provide appropriate samples. Furthermore, EM is not time-resolved, which does not allow nanoaerosol source identification or defining the emission levels of specific tasks in workplaces.

The real-time measurement of airborne nanoparticle size distribution can be performed by electrical mobility analyzers (e.g. Scanning Mobility Particle Sizer - SMPS, Fast Mobility Particle Sizer - FMPS), or, to a lesser extent, by low pressure cascade impactors (e.g. Electrical Low Pressure Impactor - ELPI) that provide less size resolution. Due to their measurement principle, SMPSs commonly require radioactive sources to set the particles in a given electrical state-of-charge. Regulations relating to the detention and transport of radioactive sources in certain countries, associated with the cost of these devices, are among the reasons for their limited use in occupational hygiene. Furthermore, according to Leskinen et al. (2012), such devices are not ideally suited for monitoring air in the workplace due to their low time resolution. Also, they are not easy- 
to-use for novices. Although recent systems (soft X-ray charger, TSI model 3087; annular Dielectric Barrier Discharge, Grimm model 5520) have been designed to avoid the use of radioactive sources, little is known about the performances of these neutralizers. In particular, the maximum concentration limit and particle losses within these devices must be documented, as must be the electrical state-of-charge of the particles described in Kallinger et al. (2012). Intensive studies of real-time instruments devoted to the measurement of airborne particle number size distribution (SMPS, FMPS) have been carried out recently (Asbach et al., 2009b; Watson et al., 2011; Joshi et al., 2012; Meier et al., 2012; Kaminski et al., 2013). Their findings highlight acceptable discrepancies between devices that can be attributed to differences in inversion algorithm, multiple charge correction, software versions, and flow rate calibration.

Several portable devices based on particle diffusion charging and sequential electrical measurement have been developed to provide airborne nanoparticle concentration and average size with higher time resolution ( $<10$ seconds) simultaneously. Examples of such devices are DiSCmini (Matter Aerosol; Fierz et al., 2011; Mills et al., 2013), Nanotracer (Philips Aerasense, discontinued; Marra et al., 2010), and nanoCheck (Grimm model 1.320).

In the absence of size-selective instruments, another approach to determine particle size is based on the simultaneous measurement of size-integrated particle concentrations (number, mass, current). Indeed, measured concentrations can also be used to determine airborne particle number size distribution. Among the key parameters governing such optimization algorithms, the shape of distribution is assumed to be lognormal with a fixed geometric standard deviation.

Although several authors (e.g. Woo et al., 2001; Maynard, 2003; Park et al., 2007a, 2007b; Park et al., 2009, 2011) have applied such methodologies to determine the surface area concentration of airborne nanoparticles, none of them has focused on the possibility of estimating the count median diameter of the aerosols and its reliability against reference data.

In this context, the present study aims at providing new results for estimating the count median diameter of airborne nanoparticles from the simultaneous measurement of the number (CPC, Grimm model 5.403) and lung-deposited surface area (NSAM, TSI model 3550) concentrations. The results were compared to SMPS data for a set of polydisperse test aerosols having three different chemical natures with count median diameters ranging from $64 \mathrm{~nm}$ to $177 \mathrm{~nm}$. 


\section{Materials and methods}

\section{Theoretical background: deriving the count median diameter from the measurement of number and lung-deposited surface area concentrations}

The instruments devoted to the measurement of airborne particle surface area concentration do not refer to the geometric surface area of the particles (Bau et al., 2012). More precisely, the lung-deposited surface area concentration, noted $C_{S, \mathrm{LD}}$, corresponds to the product of the geometric surface area concentration $\left(C_{N} \cdot \pi \cdot d_{\bar{S}}{ }^{2}\right.$ with $C_{N}$ the particle number concentration) and the probability $\left(\eta_{\mathrm{LD}}\right)$ of a particle to deposit in a given region of the respiratory apparatus:

$C_{S, \mathrm{LD}}=C_{N} \cdot \eta_{\mathrm{LD}} \cdot \pi \cdot d_{\bar{S}}{ }^{2}$

The latter deposition probabilities can be obtained from models based on experimental data (ICRP, 1994; NCRP, 1997), or from fitted simplified equations (Hinds, 1999).

Determining the diameter of average geometric surface area $\left(d_{\bar{S}}\right)$ from the last equation is complex because particle deposition probability is size-dependent, and requires the surface area per particle of given size (response function, i.e. $C_{S, \mathrm{LD}} / C_{N}$ ) to be taken into account (Ntziachristos et al., 2007). Furthermore, this function has to be monotonous with particle size to avoid multiple mathematical solutions. This was demonstrated in a previous work (Bau et al., 2012).

Assuming that the airborne particle number is distributed according to a lognormal law with given geometric standard deviation (GSD), the diameter of average geometric surface area can be used to calculate the corresponding count median diameter (CMD) by implementing the following equation (Hatch and Choate, 1929):

$d_{\bar{S}}=C M D \cdot \exp \left(\ln ^{2} G S D\right)$

It results from equations 1 and 2 that measuring in parallel the size-integrated number and lung-deposited surface area concentrations of airborne particles allows determining their count median diameter (CMD).

We performed theoretical calculations based on the response function obtained for lognormal-distributed aerosols with a GSD varying from 1.03 to 2.5 in order to provide a panel of curves allowing a wide range of possible GSDs, as shown in Figures 1 and 2. To obtain these graphs, spherical particles with unit densities were assumed in the deposition 
model from ICRP. Furthermore, aerosol size distributions were supposed to be monomodal.

The curves provide the evolution of the ratio $C_{S, \mathrm{LD}} / C_{N}$ with the GSD of an aerosol with a given CMD indicated on the right side of each curve. In other words, these graphs allow determining the CMD of an aerosol when the ratio of its lung-deposited surface area to number concentration is measured and the GSD is known (or assumed). We believe these graphs are useful for NSAM users because this approach allows both estimating and monitoring the particle count median diameter in real-time.

\section{Figures 1 and 2}

More practically, the methodology proposed in this paper relies on to the following procedure:

1) Measure in parallel the number $\left(C_{N}\right)$ and lung-deposited surface area $\left(C_{S, \mathrm{LD}}\right)$ concentrations,

2) Calculate the ratio $C_{S, \mathrm{LD}} / C_{N}$ from experimental data,

3) Assume / Set the GSD of the particle size distribution,

4) Read the corresponding CMD from Figure 1 or 2 depending on the region of the respiratory apparatus considered.

Figures 1 and 2 show that the GSD of the distribution starts affecting the theoretical response function beyond 1.4. Furthermore, for a given concentration ratio (response), increasing the GSD of the aerosol leads to a decrease in particle count median diameter. For example, monodisperse $100 \mathrm{~nm}$ particles will present the same response as a polydisperse aerosol with a modal diameter of $80 \mathrm{~nm}$ and a GSD of 1.8. Although the number size distributions are very different, the corresponding lung-deposited surface areas are similar due to the shift in the lung-deposited surface area distribution. Indeed, the latter varied with particle size according to a power law with exponent between 1.5 and 1.3 in a range from $10 \mathrm{~nm}$ to $700 \mathrm{~nm}$ for alveolar and tracheobronchial deposition, respectively.

\section{Generation, measurement setup and characterization of the test aerosols}

The accuracy of the approach was evaluated by comparing the CMD derived from measured concentrations with a reference diameter. Experiments were carried out with 
test aerosols produced by the CAIMAN (Characterisation of Aerosol Instrumentation used to Measure the Aerosols of Nanoparticles) facility, based on a spark discharge generator (PALAS GFG-1000). The elements composing this test bench and its capacity to produce nanoaerosols were described by Jacoby et al. (2011).

Three different electrodes were used in this work: carbon (graphite, pure), aluminium ( $93.11 \%$ pure), and silver (99.99\% pure). The aerosols produced were then measured simultaneously by a Scanning Mobility Particle Sizer (SMPS) and a Nanoparticle Surface Area Monitor (NSAM).

The SMPS is composed of a Differential Mobility Analyzer (DMA, Grimm Vienna Type, $\mathrm{Q}_{\text {aerosol }}=0.3 \mathrm{~L} \cdot \mathrm{min}^{-1}, \mathrm{Q}_{\text {sheath }}=3 \mathrm{~L} \cdot \mathrm{min}^{-1}$ ) equipped with an $\mathrm{Am}^{241}$ radioactive source and a Condensation Nucleus Counter (CNC, Grimm model 5.403, Q $=0.3$ L.min ${ }^{-1}$ ) placed in series to provide particle number size distributions and total number concentration (by integrating the number size distribution in all the measurement channels of the SMPS). The NSAM (TSI model 3550, Q = 2.5 L.min ${ }^{-1}$, see e.g. Fissan et al., 2007; Shin et al., 2007) provides particle lung-deposited surface area concentration in either the alveolar ('alv') or the tracheobronchial ('tb') region of the respiratory apparatus. Detailed information regarding the performances of the NSAM can be found in Asbach et al. (2009a) and Bau et al. (2009, 2011, 2012).

For the measurement of number concentrations in workplace environments, the use of a $\mathrm{CNC}$ is recommended due to its time resolution and higher portability. In our experiments, number and lung-deposited surface area concentrations measured were used to calculate the CMD of the aerosol according to the abovementioned procedure. Since both 'alv'- and 'tb'- deposited surface area concentrations were measured for each test aerosol, two CMDs were determined. This allows concluding whether 'alv'- or 'tb'-based CMDs are similar.

The number size distributions of the nanoaerosols produced were measured by the SMPS that provided the reference count median mobility diameters (CMMD). Each experimental condition was kept for 30 to 40 minutes to ensure aerosol stability and a sufficient number of scans for the determination of the average number size distribution by the SMPS. Indeed, each scan requires between 4 and 5 minutes (depending on the range of diameters covered). In the case of $\mathrm{C}$ - and Al-based aerosols, the number size distributions were corrected for variations in agglomerate charging efficiency, in line with Lall \& Friedlander (2006). The primary particle diameters used for this calculation are equal to $16 \mathrm{~nm}$ for both elements, as indicated in Bau et al. (2012). 
In addition to Henry's diagrams, chi-square statistical tests were performed on each of the number size distributions; the results highlight lognormal distributions $(\mathrm{P}<0.001)$ for all the cases of this study. For the different configurations tested, the CMMD of the polydisperse aerosols ranged from $64 \mathrm{~nm}$ to $177 \mathrm{~nm}$ (GSD from 1.45 to 1.53 ), and number concentrations ranged between $10^{4} \mathrm{~cm}^{-3}$ and $15.10^{4} \mathrm{~cm}^{-3}$, as indicated in Table 1 .

Table 1 


\section{Results and discussion}

\section{Experimental results}

To experimentally validate the approach proposed in this paper, the count median diameters derived from the ratio of lung-deposited surface area to number concentrations were compared with the count median mobility diameters obtained from SMPS measurements. Calculations were performed successively with the input of the true GSD stemming from SMPS (Figure 3a) and with a GSD set at 1.80 (Figure 3b) in agreement with different authors (Harris and Maricq, 2001; Maynard, 2003; Park et al., 2009). Additional elements relating to typical range of aerosol GSDs are provided in John (2001). Table 2 gathers measured and calculated data for a selected case (experimental condition \#13 in Table 1).

Figure 3

Table 2

Figure 3 illustrates the existence of a good correlation between count median diameters for the case of known GSDs as well as for the case of a GSD fixed at 1.8. Linear regressions carried out on the different data series present slopes between 0.94 and 1.12, associated with correlation coefficients above 0.90 . These findings indicate the possibility of estimating the diameter of a polydisperse aerosol from the simultaneous measurement of its lung-deposited surface area concentration and number concentration to within $\pm 30 \%$. This range is in agreement with the technical specifications given for example for the DiSCmini (MatterAerosol) mentioned in the introduction.

\section{Discussion and limits of the method}

For each GSD considered, the CMD stemming from 'alv'- and 'tb'-lung-deposited surface area were compared. Statistical analysis of the bias between CMD and reference CMMD is provided in Figure 4 as a Box \& Whiskers Plot. This type of graph describes the distribution of data within a population. The box surrounds the median value for the population, with limits at the first and third quartiles, while the error bars correspond to the $95 \%$ confidence interval. 
Figure 4 confirms that CMDs correlate with the reference CMMDs within $\pm 30 \%$ (only 2 data points among 80 were found beyond this interval for NSAM in 'alv' configuration with true GSD). It can be observed from Figure 4 that the NSAM configuration ('alv'- or 'tb'-lung-deposited surface area concentration) does not influence the value of the corresponding CMD, although less deposition in tb configuration. The input GSD seems to be more influent, though no statistical evidence was demonstrated. As shown in Figure 4 , the relative biases are lower (median bias closer to $0 \%$ ) for the case where GSD is set to 1.8 .

Although it was assumed that particles are spherical with unit density, no significant effect of particle composition can be highlighted, as stated earlier concerning the response functions of the NSAM in both configurations (Bau et al., 2012).

Also, it was observed that the total number concentration of the polydisperse test aerosols does not influence the diameter derived from average active or lung-deposited surface area. This point is in agreement with a previous study (Bau et al., 2012), where similar relative number size distributions with total number concentrations varying by a factor of 3 led to a factor close to 3 in the NSAM responses in both configurations $( \pm 10 \%)$.

Finally, it should be mentioned that the accuracy of the method depends on (1) the order of magnitude of the concentrations measured and (2) the associated uncertainty. More precisely, the limit of detection (LOD) of the NSAM measured with HEPA-filtered air was found to be $0.1 \mu \mathrm{m}^{2} . \mathrm{cm}^{-3}$. Considering a number concentration of $10^{3} \mathrm{~cm}^{-3}$, the methodology thus becomes applicable as soon as particles are larger than $8 \mathrm{~nm}$ and $12 \mathrm{~nm}$ for the 'alv' and 'tb' regions, respectively.

In addition, $10 \%$ uncertainty on the concentrations ratio roughly leads to $8 \%$ uncertainty on the derived CMD, whatever the configuration of the NSAM ('alv' or 'tb').

Concerning the upper size limit, theoretical calculations indicate that the response functions $\left(C_{S, \mathrm{LD}} / C_{N}\right)$ for polydisperse aerosols are no longer monotonous when their CMD reaches roughly $350 \mathrm{~nm}$ and $325 \mathrm{~nm}$ for the 'alv' and 'tb' regions, respectively. In the absence of experimental data beyond $180 \mathrm{~nm}$, it can be considered that the method is applicable in a range of sizes from $20 \mathrm{~nm}$ to $200 \mathrm{~nm}$. 


\section{Conclusion}

In the absence of real-time size-resolved instruments, measuring an aerosol in parallel with size-integrated devices can be considered to estimate its average size. Although less accurate than traditional instruments like SMPS, this approach can be useful for workplace air monitoring. Furthermore, it could be used as a screening tool to detect the presence of airborne nanoparticles (without distinction from the background aerosol).

In this work, particle lung-deposited surface area and number concentrations (CNC / NSAM) of airborne nanoparticles were used to determine their count median diameter, based on theoretical calculations for monomodal lognormal aerosols. It can be concluded from the experimental results obtained for 20 polydisperse aerosols, that the approach proposed is valid, whatever the NSAM configuration (alveolar or tracheobronchial lung deposition) and the GSD considered in the calculation. The count median diameters stemming from the calculations show acceptable relative discrepancies of $\pm 30 \%$ with a reference diameter obtained by SMPS measurements.

The main limitation of the method lies in the assumption of monomodal lognormal size distribution. Furthermore, data involving aerosols with CMMD beyond $180 \mathrm{~nm}$ and with a GSD above 1.6 should be produced and analyzed to extend our observations. 


\section{References}

Asbach C., Fissan H., Stahlmecke B., Kuhlbusch T.A.J. and Pui D.Y.H. (2009a). Conceptual limitations and extensions of lung-deposited Nanoparticle Surface Area Monitor (NSAM). Journal of Nanoparticle Research 11: 101-109.

Asbach C., Kaminski H., Fissan H., Monz C., Dahmann D., Mülhopt S., Paur H.R., Kiesling H.J., Herrmann F., Voetz M. and Kuhlbusch T.A.J. (2009b). Comparison of four mobility particle sizers with different time resolution for stationary exposure measurements. Journal of Nanoparticle Research 11: 1593-1609.

Bau S., Witschger O., Gensdarmes F. and Thomas D. (2009). Experimental study of the response functions of direct-reading instruments measuring surface-area concentration of airborne nanostructured particles. Journal of Physics: Conference Series 170: 012006. DOI: 10.1088/1742-6596/170/1/012006.

Bau S., Witschger O., Gensdarmes F. and Thomas D. (2011). Response of three instruments devoted to surface-area for monodisperse and polydisperse aerosols in molecular and transition regimes. Journal of Physics: Conference Series 304: 012015. DOI: 10.1088/1742-6596/304/1/012015.

Bau S., Witschger O., Gensdarmes F. and Thomas D. (2012). Evaluating three directreading instruments based on diffusion charging to measure surface area concentrations in polydisperse nanoaerosols in molecular and transition regimes. Journal of Nanoparticle Research 14: 1217-1233.

Brouwer D., Van Duuren-Stuurman B., Berges M., Jankowska E., Bard D. and Mark D. (2009). From workplace air measurement results towards estimates of exposure? Development of a strategy to assess exposure to manufactured nano-objects. Journal of Nanoparticle Research 11: 1867-1881.

Fierz M., Houle C., Steigmeier P. and Burtscher H. (2011). Design, calibration, and field performance of a Miniature Diffusion Size Classifier. Aerosol Science and Technology 45: 1-10.

Fissan H., Neumann S., Trampe A., Pui D.Y.H. and Shin W.G. (2007). Rationale and principle of an instrument measuring lung deposited nanoparticle surface area. Journal of Nanoparticle Research 9: 53-59.

Hatch T. and Choate S.P. (1929). Statistical description of the size properties of nonuniform particulate substances. J. Franklin Inst. 207:369-387.

Harris S.J. and Maricq M.M. (2001). Signature Size Distributions for Diesel and Gasoline Engine Exhaust Particulate Matter. Aerosol Science and Technology 32:749-764.

Hinds W.C. (1999). Aerosol Technology. Properties, behavior and measurement of airborne particles ( $2^{\text {nd }}$ Edition), New York: John Wiley \& Sons, 483 p. 
ICRP (1994). Publication 66: Human respiratory tract model for radiological protection.

Oxford: Pergamon.

Jacoby J., Bau S. and Witschger O. (2011). CAIMAN: a versatile facility to produce aerosols of nanoparticles. Journal of Physics: Conference Series 304: 012014. doi: 10.1088/1742-6596/304/1/012014.

Joshi M., Sapra B.K., Khan A., Tripathi S.N., Shamjad P.M., Gupta T. and Mayya Y.S. (2012). Harmonisation of nanoparticle concentration measurements using Grimm and TSI scanning mobility particle sizers. Journal of Nanoparticle Research 14: $1268-1281$.

John W. (2001). Size distribution characteristics of aerosols, in: Baron P.A. and Willeke K. (Eds), Aerosol Measurement: Principles, Techniques and Applications ( $2^{\text {nd }}$ Ed.). New York: Wiley Interscience, pp. 99-116.

Kallinger P., Steiner G. and Szymanski W.W. (2012). Characterization of four different bipolar charging devices for nanoparticle charge conditioning. Journal of Nanoparticle Research 14: 944-951.

Kaminski H., Kuhlbusch T.A.J., Rath S., Götz U., Sprenger M., Wels D., Polloczek J., Bachmann V., Dziurowitz N., Kiesling H.J., Schwiegelsohn A., Monz C., Dahmann D. and Asbach C. (2013). Comparability of mobility particle sizers and diffusion chargers. Journal of Aerosol Science 57: 156-178.

Lall A.A. and Friedlander S.K. (2006). On-line measurement of ultrafine aggregate surface area and volume distributions by electrical mobility analysis: I. Theoretical analysis. Journal of Aerosol Science 37: 260-271.

Leskinen J., Joutsensaari J., Lyyränen J., Koivisto J., Ruusunen J., Järvelä M., Tuomi T., Hämeri K., Auvinen A. and Jokiniemi J. (2012). Comparison of nanoparticle measurement instruments for occupational health applications. Journal of Nanoparticle Research 14: 718-733.

Marra J., Voetz M. and Kiesling H.J. (2010). Monitor for detecting and assessing exposure to airborne nanoparticles. Journal of Nanoparticle Research 12: 21-37.

Mavrocordatos D., Perret D. and Leppard G.G. (2007). Strategies and advances in the characterisation of environmental colloids by electron microscopy, in: Wilkinson K.J. and Lead J.R., Environmental colloids: behaviour, structure and characterization, IUPAC Series on Analytical and Physical Chemistry of Environmental Systems 10: 345-396.

Maynard A.D. (2003) Estimating aerosol surface-area from number and mass concentration measurements. Annals of Occupational Hygiene 47: 123-144. 
Meier R., Clark K. and Riediker M. (2012). Comparative testing of a Miniature Diffusion Size Classifier to assess airborne ultrafine particles under field conditions. Aerosol Science and Technology 47: 22-28.

Methner M., Hodson L., Geraci C. (2010). Nanoparticle emission assessment technique (NEAT) for the identification and measurement of potential inhalation exposure to engineered nanomaterials - part A. Journal of Occupational and Environmental Hygiene 7: 127-132.

Mills J.B., Park J.H. and Peters T.M. (2013). Comparison of the DiSCmini aerosol monitor to a handheld condensation particle counter and a scanning mobility particle sizer for submicrometer sodium chloride and metal aerosols. Journal of Occupational and Environmental Hygiene 10, in press.

NCRP (1997). Deposition, retention and dosimetry of inhaled radioactive substances, Report S.C. 57-2, NCRP, Bethesda, MD.

Ntziachristos L., Polidori A., Phuleria H., Geller M.D. and Sioutas C. (2007). Application of diffusion charger to the measurement of particle surface concentration in different environments. Aerosol Science and Technology 41: 571-580.

Park D., An M. and Hwang J. (2007a). Development and performance test of a unipolar diffusion charger for real-time measurements of submicron aerosol particles having a log-normal size distribution. Journal of Aerosol Science 38: 420-430.

Park D., Kim S., An M. and Hwang J. (2007b). Real-time measurement of submicron aerosol particles having a lognormal size distribution by simultaneously using unipolar diffusion charger and unipolar field charger. Journal of Aerosol Science 38: $1240-1245$.

Park J.Y., Ramachandran G., Raynor P.C. and Kim S.W. (2011). Estimation of surface area concentration of workplace incidental nanoparticles based on number and mass concentrations. Journal of Nanoparticle research 13: 4897-4911.

Park J.Y., Raynor P.C., Maynard A.D., Eberly L.E. and Ramachandran G. (2009). Comparison of two estimation methods for surface area concentration using number concentration and mass concentration of combustion-related ultrafine particles. Atmospheric Environment 43: 502-509.

Ramachandran G., Ostraatb M., Evans D. E., Methner M. M., O'Shaughnessy P., D'Arcy J., Geraci C. L., Stevenson E., Maynard A. D. and Rickabaugh K. (2011). A Strategy for Assessing Workplace Exposures to Nanomaterials, Journal of Occupational and Environmental Hygiene 8: 673-685.

Shin W.G., Pui D.Y.H., Fissan H., Neumann S. and Trampe A. (2007). Calibration and numerical simulation of Nanoparticle Surface Area Monitor (TSI model 3550 NSAM). Journal of Nanoparticle Research 9: 61-69. 
Wang J., Asbach C., Fissan H., Hülser T., Kuhlbusch T.A.J., Thompson D. and Pui D.Y.H. (2011). How can nanobiotechnology oversight science and industry: examples from environmental, health, and safety studies of nanoparticles (nanoEHS). Journal of Nanoparticle Research 13: 1373-1387.

Watson J.G., Chow J.C., Sodeman D.A., Lowenthal D.H., Chang M.C.O., Park K. and Wang X. (2011). Comparison of four scanning mobility particle sizers at the Fresno Supersite. Particuology 9: 204-209.

Witschger O., LeBihan O., Reynier M., Durand C., Marchetto A., Zimmermann E. and Charpentier D. (2012). Préconisations en matière de caractérisation des potentiels d'émission et d'exposition professionnelle aux aérosols lors d'opérations mettant en œuvre des nanomatériaux, Hygiène et Sécurité au Travail 226: 41-55 (in French).

Woo KS, Chen DR, Pui DYH, Wilson WE (2001) Use of continuous measurements of integral aerosol parameters to estimate particle surface area. Aerosol Science and Technology 34: 57-65. 
Table 1. Characteristics of the polydisperse test aerosols produced with CAIMAN.

\begin{tabular}{|c|c|c|c|c|}
\hline Condition & Electrode & $\begin{array}{l}\text { CMMD } \\
(\mathbf{n m})\end{array}$ & $\begin{array}{l}\text { GSD } \\
(-)\end{array}$ & $\begin{array}{l}C_{N} \pm s\left(C_{N}\right)^{a} \\
\left(10^{4} \mathrm{~cm}^{-3}\right)\end{array}$ \\
\hline 1 & $\mathrm{C}$ & 110 & 1.49 & $13.66 \pm 0.24$ \\
\hline 2 & $\mathrm{C}$ & 164 & 1.49 & $3.90 \pm 0.32$ \\
\hline 3 & $\mathrm{C}$ & 72 & 1.45 & $1.58 \pm 0.02$ \\
\hline 4 & $\mathrm{C}$ & 183 & 1.50 & $8.37 \pm 0.20$ \\
\hline 5 & $\mathrm{C}$ & 156 & 1.50 & $7.99 \pm 0.16$ \\
\hline 6 & $\mathrm{C}$ & 159 & 1.50 & $6.38 \pm 0.11$ \\
\hline 7 & $\mathrm{C}$ & 160 & 1.49 & $4.72 \pm 0.07$ \\
\hline 8 & $\mathrm{C}$ & 177 & 1.49 & $1.96 \pm 0.09$ \\
\hline 9 & $\mathrm{C}$ & 173 & 1.50 & $2.21 \pm 0.03$ \\
\hline 10 & $\mathrm{C}$ & 177 & 1.50 & $1.76 \pm 0.04$ \\
\hline 11 & $\mathrm{C}$ & 148 & 1.45 & $4.90 \pm 0.10$ \\
\hline 12 & $\mathrm{C}$ & 125 & 1.46 & $2.21 \pm 0.06$ \\
\hline 13 & $\mathrm{C}$ & 129 & 1.46 & $1.19 \pm 0.03$ \\
\hline 14 & $\mathrm{Ag}$ & 73 & 1.53 & $4.74 \pm 0.05$ \\
\hline 15 & $\mathrm{Ag}$ & 65 & 1.53 & $8.46 \pm 0.08$ \\
\hline 16 & $\mathrm{Ag}$ & 64 & 1.53 & $14.93 \pm 0.23$ \\
\hline 17 & $\mathrm{Ag}$ & 66 & 1.53 & $4.91 \pm 0.05$ \\
\hline 18 & $\mathrm{Al}$ & 109 & 1.53 & $6.13 \pm 0.10$ \\
\hline 19 & $\mathrm{Al}$ & 91 & 1.53 & $4.06 \pm 0.05$ \\
\hline 20 & $\mathrm{Al}$ & 92 & 1.53 & $2.56 \pm 0.02$ \\
\hline
\end{tabular}

${ }^{a} \mathrm{~s}\left(\mathrm{C}_{\mathrm{N}}\right)$ corresponds to the standard deviation of the total number concentration observed for the successive scans. 
Table 2. Example of experimental and calculated data for Condition 13.

\begin{tabular}{ll}
\hline Parameter & Value \\
\hline Measured 'alv'-deposited surface area concentration & $130.0 \mu \mathrm{m}^{2} / \mathrm{cm}^{3}$ \\
Measured 'tb'-deposited surface area concentration & $33.9 \mu \mathrm{m}^{2} / \mathrm{cm}^{3}$ \\
Measured number concentration & $11949 \mathrm{~cm}^{-3}$ \\
Measured CMMD & $129 \mathrm{~nm}$ \\
Measured GSD & 1.46 \\
Calculated ratio $\boldsymbol{C}_{\boldsymbol{S}, \mathbf{L D}} / \boldsymbol{C}_{\boldsymbol{N}}$ in 'alv' configuration & $0.0109 \mu \mathrm{m}^{2}$ \\
Calculated ratio $\boldsymbol{C}_{\boldsymbol{S}, \mathbf{L D}} / \boldsymbol{C}_{\boldsymbol{N}}$ in 'tb' configuration & $0.0028 \mu \mathrm{m}^{2}$ \\
Calculated CMD in 'alv' configuration with known GSD (1.46) & $149 \mathrm{~nm}$ \\
Calculated CMD in 'tb' configuration with known GSD (1.46) & $156 \mathrm{~nm}$ \\
Calculated CMD in 'alv' configuration with fixed GSD (1.8) & $123 \mathrm{~nm}$ \\
Calculated CMD in 'tb' configuration with fixed GSD (1.8) & $134 \mathrm{~nm}$ \\
\hline
\end{tabular}




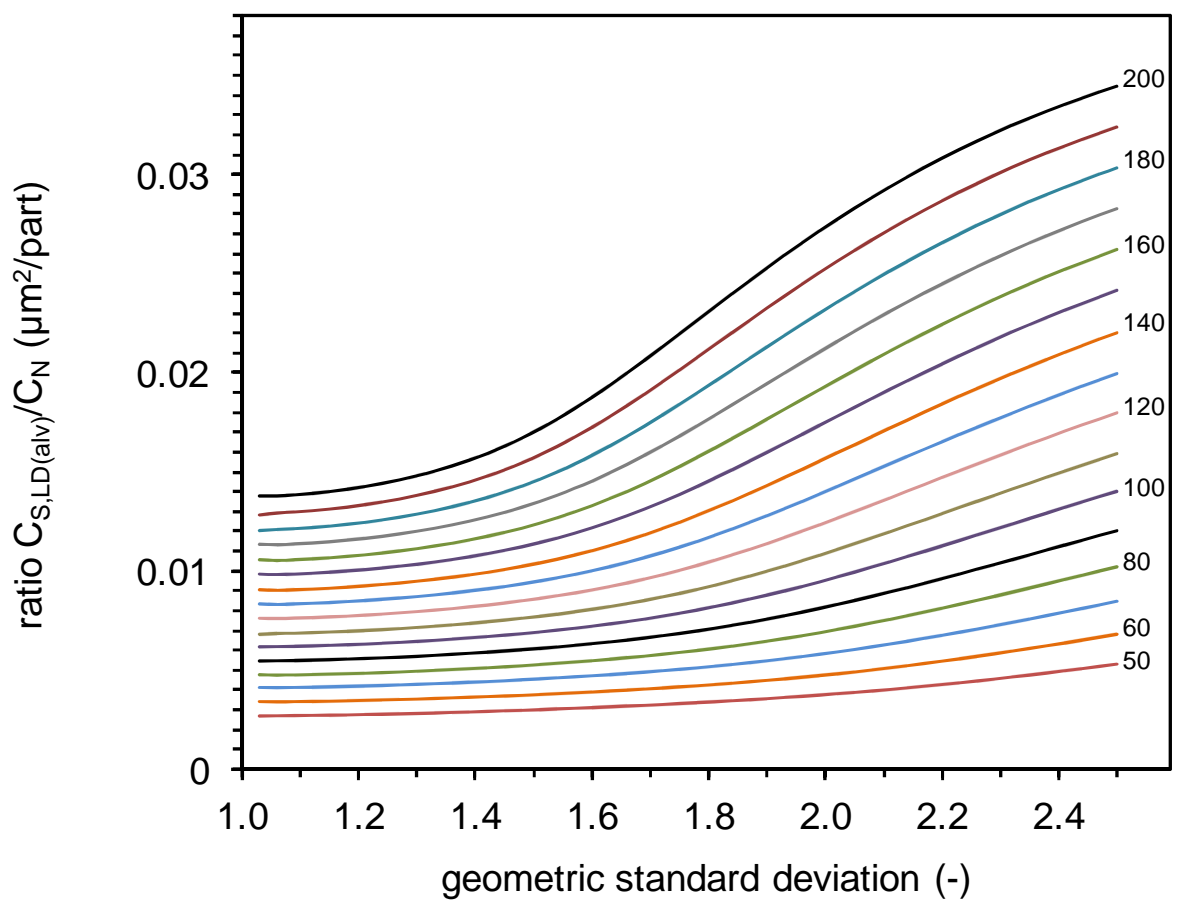

Figure 1. Evolution of the alveolar lung-deposited surface area per particle with the geometric standard deviation of the aerosol size distribution for different count median diameters (indicated on the right in $\mathrm{nm})$. 


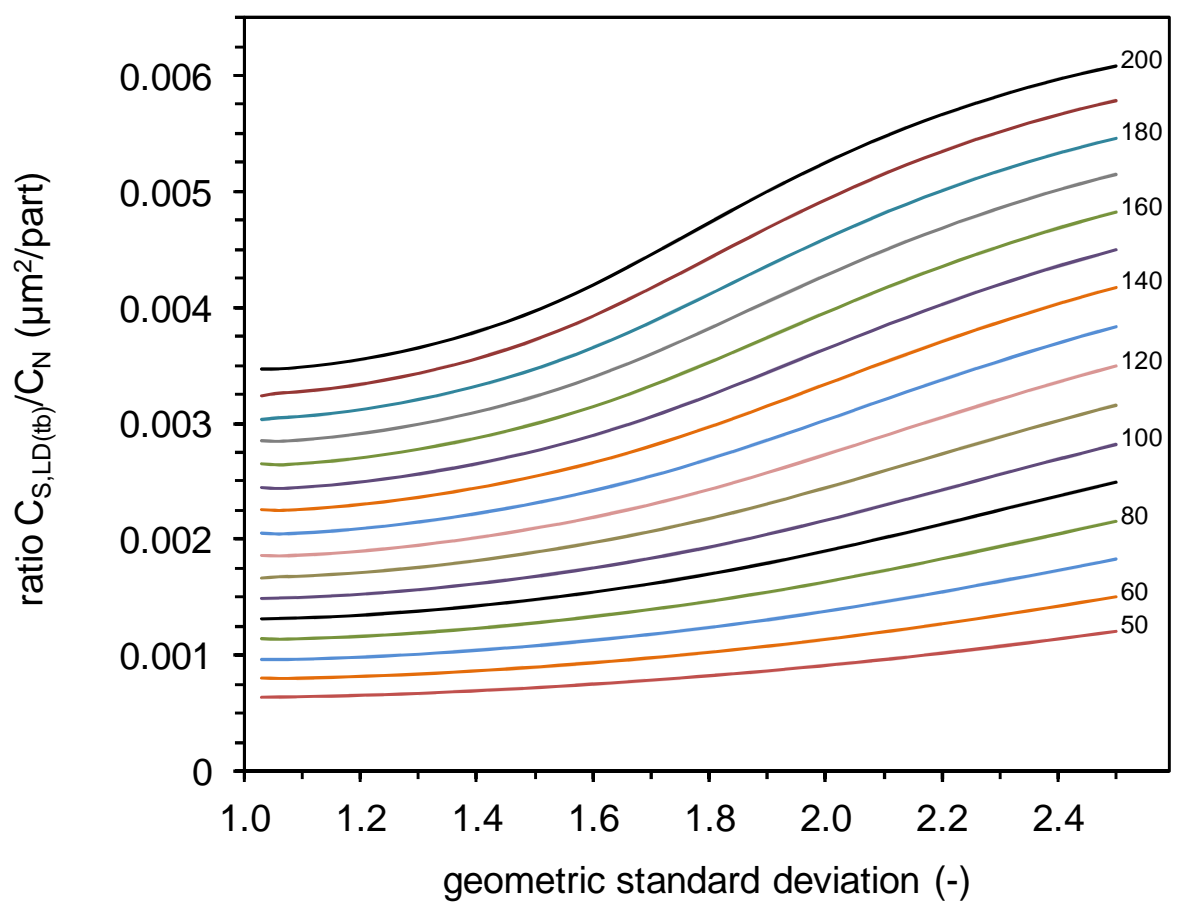

Figure 2. Evolution of the tracheobronchial lung-deposited surface area per particle with the geometric standard deviation of the aerosol size distribution for different count median diameters (indicated on the right in $\mathrm{nm}$ ). 
(a)

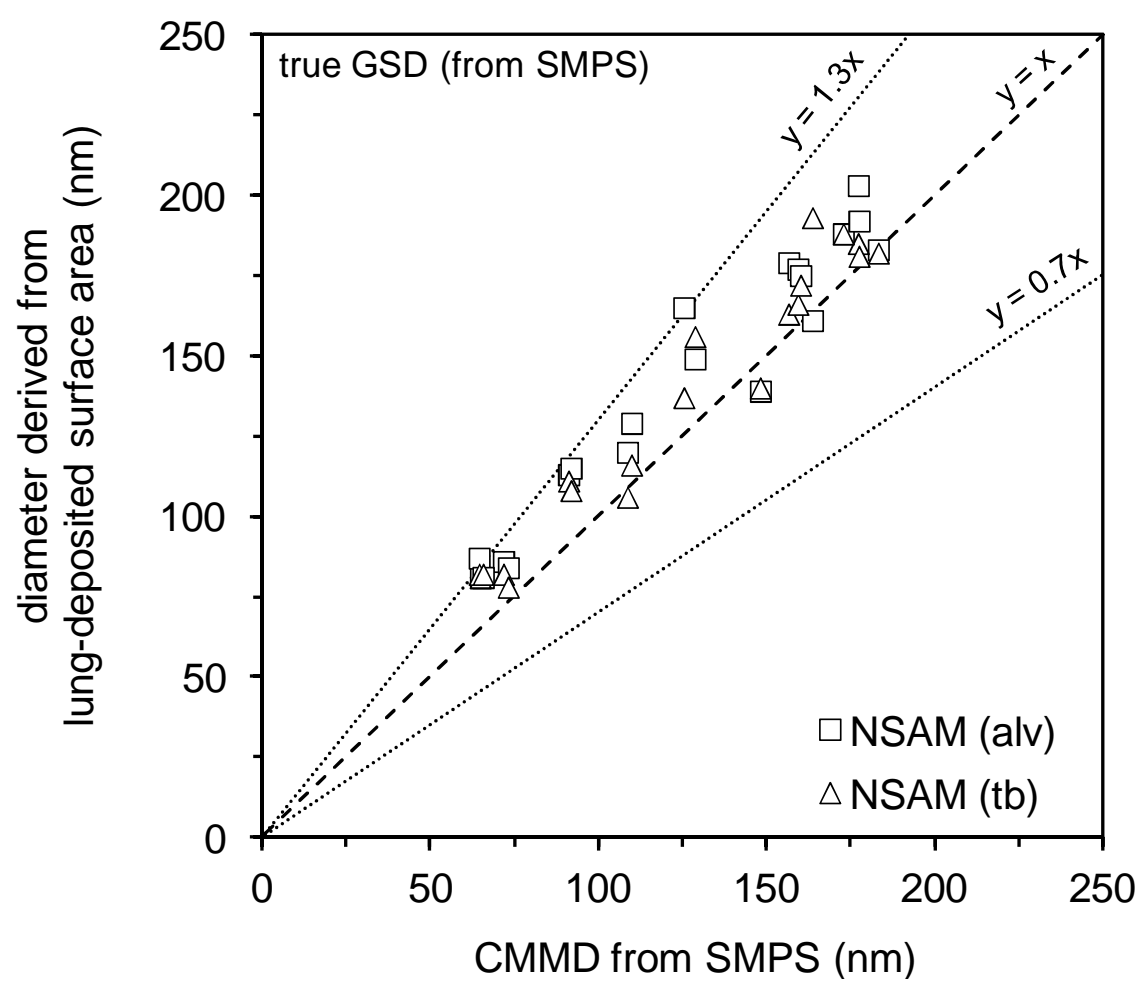

(b)

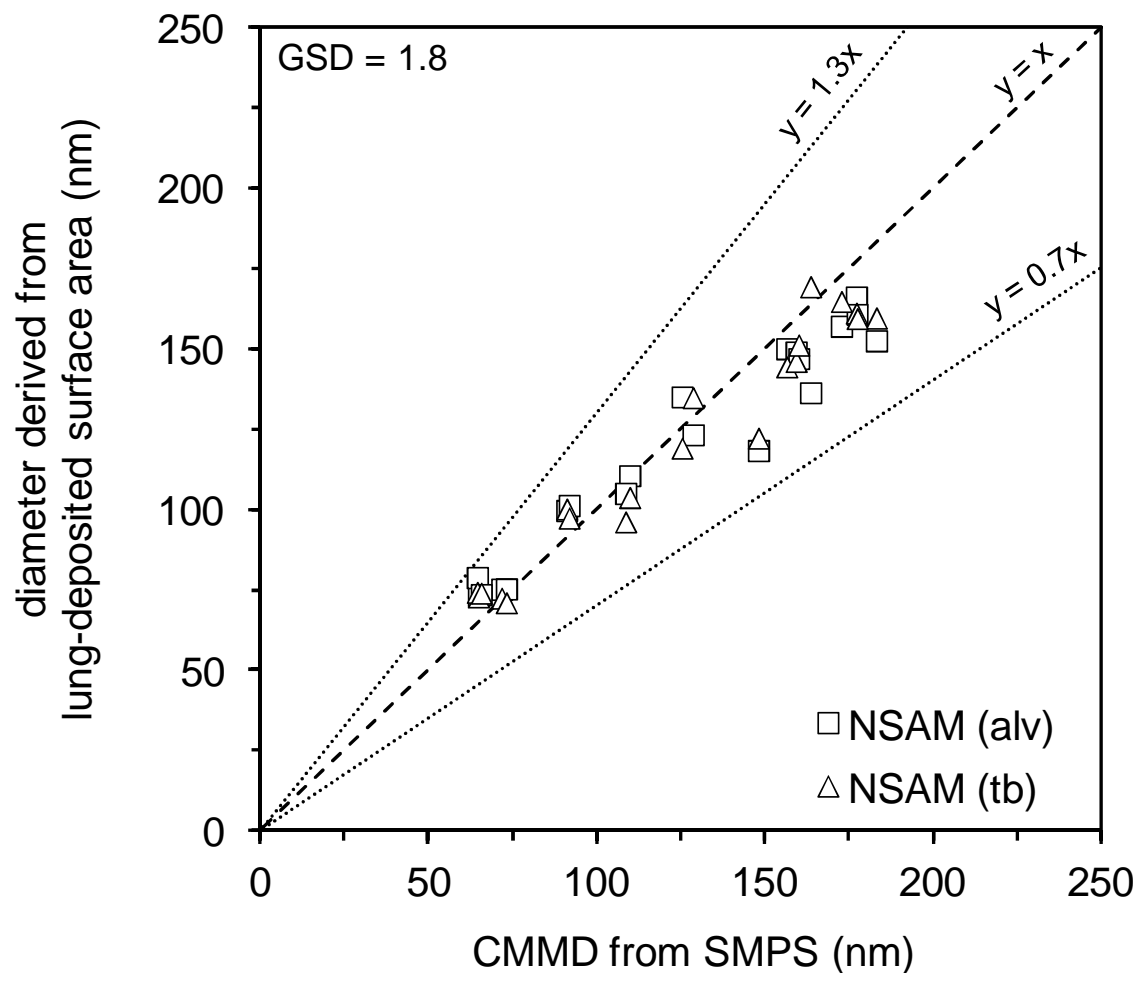

Figure 3. Comparison of the count median diameters derived from lung-deposited surface-area and the count median mobility diameters from SMPS measurements. (a) calculation performed with the input of the true GSD, (b) calculation performed with a GSD set at 1.8. Each data series gathers the results obtained for all chemical substances. The dotted lines correspond to deviations from the bisecting line of $\pm 30 \%$. 


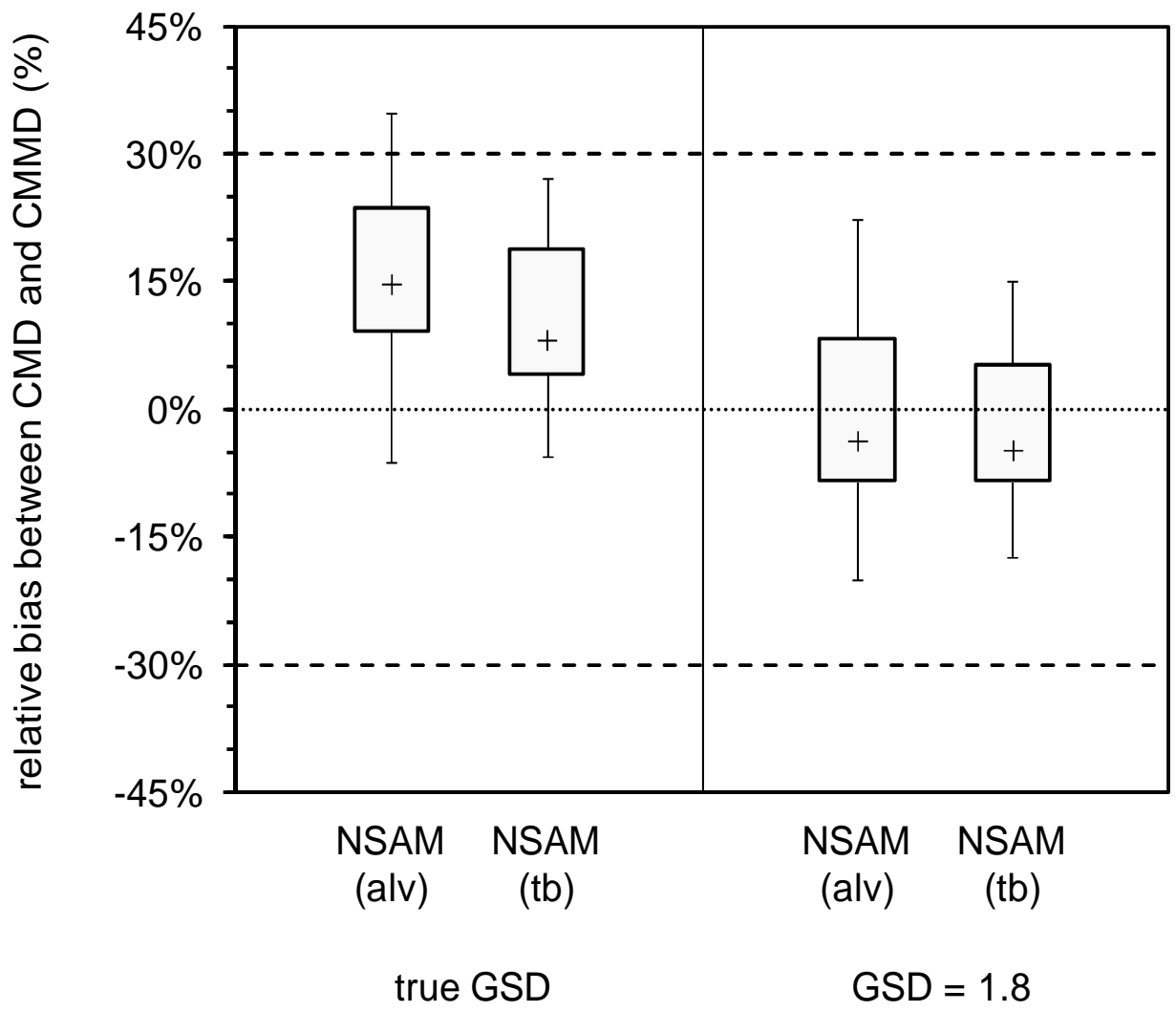

Figure 4. Box \& Whiskers plot of the relative differences between calculated and reference median diameters for both configurations of the NSAM ('alv' and 'tb') and the two GSDs considered. 